\title{
Sexual life assessment in individuals with different kind of relationships
}

\author{
Evaluación de la vida sexual en personas con diferentes tipos de relaciones
}

\author{
Kumrije Gagica ${ }^{1}$, Hajrullah Fejza ${ }^{2}$
}

\begin{abstract}
Sexual life and intimacy mainly is based by one's personality, knowledge and attitudes toward others. Someone's personality can tell us how they approach all sorts of different things in life, including sexual life. To audit sexual life it is necessary to assess it through asking people who have a regular partner or whoever they are having sex, or their last relationship. The study included 500 subjects from Albania and Kosovo. The questionnaire was delivered through Survey planet app. The audit was opened during June 2019. Questionnaire contains 15 questions with A, B, C alternatives. The data were analyzed through SPSS software. Using the program, a series of Student's $t$-tests was conducted for independent samples and correlation analysis with Pearson's coefficient. The answers were categorized in three categories: mostly A, mostly B and mostly C. Female respondents were $54.6 \%$ whereas 45.4\% male. The majority, $78 \%$ ranked in age group 21-50 years old, from whom $71.4 \%$ were married. Mostly A score frequently found at $53.60 \%$ of participants which sounds like they and their partners have a really healthy and satisfying sex life. "Mostly B" answered by $32 \%$ of participants which means that they were mostly satisfied with their sex life, and it seems like sometimes they can feel a little disconnected. Mostly $C$ score is most commonly found at $14.40 \%$ of participants. This study shows that more than a half of the participants have a satisfying and a healthy sexual life.
\end{abstract}

Key Words: psychology, sexual life, intimacy, feelings about sexual life

\section{RESUMEN}

La vida sexual y la intimidad se basan principalmente en la personalidad, el conocimiento y las actitudes hacia los demás. La personalidad de alguien puede decirnos cómo abordan situaciones diferentes en la vida, incluida la vida sexual. Para estudiar la vida sexual es necesario evaluarla preguntando a las personas que tienen una pareja regular o con quienes están teniendo relaciones sexuales, o su última relación. El estudio incluyó 500 sujetos de Albania y Kosovo. El cuestionario se entregó a través de la aplicación Survey planet. La evaluación se realizó durante junio de 2019. El cuestionario contiene 15 preguntas con alternativas A, B, C. Los datos fueron analizados a través del software SPSS. Utilizando el programa, se realizó una serie de pruebas t de Student para muestras independientes y análisis de correlación $\mathrm{R}$ de Pearson. Las respuestas se clasificaron en tres categorías: en su mayoría A, en su mayoría B y en su mayoría C. Las personas encuestadas fueron $54.6 \%$ mujeres y $45.4 \%$ hombres. El 78\% se clasificó en el grupo de edad de 21 a 50 años, de los cuales el 71,4\% estaban casados. En su mayoría A tuvo un porcentaje del $53.60 \%$ de participantes quienes señalaron que ellos(as) y sus parejas tienen una vida sexual realmente saludable y satisfactoria. "En su mayoría B" respondieron el $32 \%$ de participantes, lo que significa que estaban mayormente satisfechos(as) con su vida sexual, pero que a veces pueden sentirse un poco desconectados(as). En su mayoría C respondió el $14.40 \%$ de participantes. Este estudio muestra que más de la mitad de las personas participantes tienen una vida sexual satisfactoria y saludable.

Palabras clave: Psicología. vida sexual, intimidad, sentimientos sobre la vida sexual.

\footnotetext{
${ }^{1}$. University of Pristina, the Faculty of Philosophy, Dept. of Social Work, Prishtina, Kosovo. Email: kumrije.gagica@uni-pr.net

${ }^{2}$. University for Business and Technology (UBT)-Higher Education Institution, Prishtina, Kosovo. Email:. hajrullah.fejza@ubt-uni.net
} 


\section{Introduction}

Sexual life and intimacy mainly is based by one's personality, knowledge and attitudes toward others. Someone's personality can tell us how they approach all sorts of different things in life, including sexual life. To audit sexual life it is necessary to assess it through asking people who have a regular partner or whoever they are having sex, or their last relationship. Since personality is highly heritable, if personality is correlated to sexual interests, then sexuality must also be at least somewhat heritable. So, understanding sexuality through the prism of personality helps us to honor and respect individual differences.

Specifically, a large body of research suggests that our sex lives are partially shaped by five basic dimensions of personality known commonly as the Big Five traits which includes openness to experience, conscientiousness, extraversion, agreeableness, and neuroticism Openness helps people to have greater willingness to try new things, they report more liberal sexual attitudes and are more willing to acknowledge when they have same-sex attractions. Conscientious people report being more sexually satisfied and are less likely to develop sexual problems, perhaps because their attention to detail carries over into the bedroom in ways that enhance sex. Extraverted people are very sociable and outgoing. They like to get out and interact with the world around them. Agreeable people in other hand seem less interested in sex they report less desire, less frequent sex, and less casual sex. Lastly, neurotic individuals tend to be on the emotionally unstable side. As might imagine, not dealing well with stress and being quick to get annoyed isn’t a recipe for a happy or healthy sex life (Lehmiller, 2018).We wanted to find out where, in which of this characteristics belong our participants depending on their response through sexual life satisfaction audit.

Social aspects deal with the effects of human society on one's sexuality, while spirituality concerns the individual's spiritual connection with others. Sexuality also affects and is affected 
by cultural, political, legal, philosophical, moral, ethical, and religious aspects of life (Aaron,2017). The more that we understand how and why different people approach sex in different ways, the better equipped we will be to develop interventions designed to improve sexual health. Not enough studies were done worldwide in audit or assessing sexual and intimacy life. Studies on sexual life quality are dominated by the pathogenic paradigm (Bachmann, 2008). In this approach, sexual satisfaction is usually defined negatively as a lack of dissatisfaction (Renaud,2000). Similarly, in the pathogenic paradigm, one's health is understood as having no disorders or diseases. Stephenson's (2010) have demonstrated that among a given clinical group, orgasm was not associated with satisfaction. It was, instead, conditioned by general arousal and lubrication. Importantly, correlating satisfaction with orgasm often considered as an indicator was not statistically significant. The above confirms the hypothesis that sexual satisfaction is highly personal, and is difficult to measure with indicators chosen arbitrarily. An individual's sexual experience and behavior can be explained by sexual needs and personality traits which can further or hinder sexual satisfaction. Relate's Counselors (2017) who compiled the test which we used for this audit, found that many of us go through life without really considering how much pleasure we are getting. Or perhaps you worry that you are not "doing it right" - not having enough, or being experimental enough, or "performing" well. You may also wonder if your partner (or partners) is satisfied with your sexual performance whether they are wondering if sex might be better with someone else. Sexual health remains a continuing concern for all adults, regardless of age. On a recently published study Wallace (2008) by a nationally representative sample of 3,005 older adults in the United States showed that $26 \%$ of Americans between the ages of 75 and 85 were sexually active (having had sex at least once in the previous year). They also found that sexual activity decreases with age: for example, $73 \%$ of those between 57 and 64 years of age and $53 \%$ of those between 65 and 74 were active. 
Sexuality assessment and considerations in older adults is sorely lacking in medical care and rehabilitation, let alone in older adults who reside in long term care facilities (American Bar Association American Psychological Association, 2008). It's important to keep in mind that looking at the overall pattern of traits an individual person exhibits is probably more informative than looking at specific traits in isolation. For example, just because you are an introverted person does not necessarily mean you're unhappy with your sex life especially if you happen to be an introvert who is agreeable and open to new experiences.

McClelland (2010) from Michigan University state that over the past 20 years, sexual quality of life has become of increasing interest to psychologists studying quality of life with ill and/or aging populations. As people are living longer with chronic illnesses, the maintenance of sexual health has become a topic of concern and an essential domain of overall quality of life. She defines sexual quality of life as encompassing multiple dimensions that an individual may associate with a healthy and pleasurable sexual life. These include sexual responses, cognitions, and attitudes, as well as dimensions related to intimate relationships and a sense of one's physical body as capable and entitled to experiencing sexual sensations. The physiological dimension of sexual response and genital response in particular has often dominated sexual function research.

Although numerous sexuality researchers have documented various aspects and predictors of sexual satisfaction, few public health researchers have integrated this concept into their studies, programs, or policies. Even within the sexuality field, few studies have assessed aspects of sexual satisfaction specific to young adults; most studies have focused on adult populations. Factors consistently associated with satisfaction in adults may not influence sexual satisfaction in the same way for young people just beginning their sexual lives. Such factors includes: age, frequency of sexual activity and orgasm; relationship status, stability, and intimacy; more permissive sexual attitudes; psychological well-being and depressive symptoms; and sexual 
function or dysfunction. Additional factors studied among young people include sexual guilt, especially among young women and goal setting (Higgins, 2011).

Satisfaction with sexual life and sexual relationship with a partner is a significant factor determining the quality of a marital relation. Many authors think that sexual intercourse between spouses is the core constituent of a relationship, which allows them to develop love and a marital bond, and they find the quality of sexual initiation to be the most important factor conditioning further happiness in marital sexual life. Partnership relations, behavioral patterns, mood, and sexuality of women changed during their lifespan especially in pregnancy but a sexual relationship between partners is considered to be a source of valuable psychological benefits, which improve the quality of life. That is, the higher the quality of sexual life, the greater is the involvement of spouses in daily life issues, accompanied by a greater degree of mutual emotional expression between spouses (Lutkiewicz, 2013).

Various factors such as physiology, motive, experience, beliefs, lifestyle, and proper relationships could have an impact on women sexual life. If there is a case that some of these elements are not enough present it can have a negative effect on the female sexual functioning and consequently will affect the couples lifes. Sometimes, the dissatisfactions unexpressed at the presence of sexual dysfunctions can cause the strain on the relationship between the couple even resultant to divorce (Mogharab, 2019). Married couples in China now tend to pay more attention to the quality of their marriage, rather than its stability alone. From 1982 to 1994, the divorce rate in China increased annually by more than $10 \%$. About $30 \%$ of divorced people attributed their break up to sexual difficulties. Increasingly, women who are dissatisfied with their sex life, especially those with higher education levels, will initiate extramarital relationships or divorce (Cheung, 2005). It has been reported that low sexual function adversely affects women's quality of life and interpersonal relationships. Sexual function in women is determined by multiple aspects, including biological, medical, and psychological factors. It is 
also associated with socio-demographic and also behavioral characteristics of women, such as degree of education and physical activity. One's relationship with a partner and the length of marriage has a great impact on sexual function (Zhang,2017).

The West Balkan Countries are known as a more conservative region regarding sexuality and sexuality education. This could produce different opinions among participants when they have to speak about sexual life. It is thought that sexuality is more presumed as a way for reproduction and not for recreation and pleasure. Our purpose in this study was to find out how this matter is spread among population which does not have a lot of knowledge about sexuality.

\section{Matherials and methods}

The questionnaire named "Are you happy in the bed “compiled by Relate's counsellors (https://www.relate.org.uk/), addresses sexual satisfaction through three main responses in which psychometric qualities may be found depending on the participants' response. The study included 500 subjects from Albania and Kosovo. The questionnaire was delivered through Survey planet app. The audit was opened during June 2019. Demographic data included sex, age and marital status. Female participants were $54.6 \%$ while $54.4 \%$ were male. The age of participants was divided into three categories: 0-20 year, 21-50 and over 50. Marital status was defined as single, in an intimate relationship and married. After that, a 15 questions with three alternatives were used to describe different state of emotions, feelings, communication, intimacy, previous talks with parents about sexuality, sexual performance among others. Those questions consist of A, B, C alternatives.

The questionnaire was translated into Albanian language, socio-demographics characteristics were added and again translated into English by the Royal School of English in Prishtina. After that the probe test was done among 30 participants who are not included in the study. 
The data was analyzed through SPSS software. Using the program a series of Student's $t$-tests was conducted for independent samples and correlation analysis with Pearson's coefficient. The answers were categorized in three categories: mostly A, mostly B and mostly C.

Mostly A answers- sounds like partners have a really healthy and positive sex life. They are willing to be open about what they want from sex, and do not find it too difficult to express this. They are also intimate with each other more generally - being open with emotions, comfortable in each other's company and able to express affection. This helps them feel close. Mostly B - While they are mostly satisfied with sexual life, it sounds like sometimes partners can feel a little disconnected. Maybe there are things that they would like to change, but they are not sure how to start the conversation. Perhaps they feel awkward about it or are worried about hurting partner's feelings. Likewise, it sounds like there is a bit of an emotional gap between partners. Maybe they are open with emotions on the overall, but perhaps avoid certain topics, such as satisfaction.

Mostly C -It sounds like there is a real distance between partners, both sexually and emotionally. Maybe they feel unable to talk about sex openly. Fear of performance or the possibility of being rejected by a partner makes them feel anxious and consequently may not experience proper sexual pleasure. They may have got into the habit of thinking of it as a "performance" that might easily go wrong - or even a burden that have to endure. It also sounds like they are keeping emotions bottled up or getting into fights whenever there is a disagreement. Perhaps things have got to the point where they feel generally uncomfortable around each other - where day-to-day tensions make life difficult and stressful.

To ascertain the possible links between these three responses to personality we have analyzed the Big Five personality traits in each of these by describing in a different way that is incorporation of findings into personality factors. Most researchers so far have made the 
standard comparison by looking at the impact of personality on sex life while we have tried to explain potential personality factors through the study findings.

\section{Results}

There is no significant sex difference among the participants while the age group 21-50 was highly represented (78 \%) followed by participants over 50 years old (19.4\%). Marital status as married was found to be among $71.4 \%$ of participants while single were $8.8 \%$ of them, (Table 1).

Table 1

Participants demographic data

\begin{tabular}{cccccc} 
& & $\mathrm{Nr}(500)$ & $\%$ & Confidence Interval \\
\hline Sex & $\mathrm{F}$ & 273 & 54.6 & 50.2 & 59 \\
\hline & $\mathrm{M}$ & 227 & 45.4 & 41 & 49.8 \\
\hline Age & $0-20$ & 13 & 2.6 & 0.7 & 1.2 \\
\hline & $21-50$ & 390 & 78 & 74.4 & 81.6 \\
\hline & $50+$ & 97 & 19.4 & 16.2 & 23.2 \\
\hline Marital & Married & 357 & 71.4 & 67.6 & 75.4 \\
\hline status & Single & 44 & 8.8 & 6.4 & 11.4 \\
\hline & $\begin{array}{c}\text { In a } \\
\text { relation }\end{array}$ & 99 & 19.8 & 16.2 & 23.2 \\
\hline & & & & &
\end{tabular}

Analyzing the sexual life of our subjects we can conclude that mostly A score frequently found at $53.60 \%$ of participants which could meant that participants and their partners have a really healthy and satisfying sex life. On the other hand, $32 \%$ of participants responded "mostly B", which means that they are mostly satisfied with their sex life, and it seems like sometimes they can feel a little disconnected. Mostly $C$ score frequently found at $14.40 \%$ of participants. So, it can be said that there is a real distance between them and their partner, both sexually and emotionally, (Table 2). 
Table 2

Participant answers -three main groups

\begin{tabular}{lrrr}
\multicolumn{2}{c}{ Answer } & $\%$ & P values \\
\hline Mostly & A & 53.6 & \\
Mostly & B & 32.0 & $<0.005$ \\
Mostly & C & 14.4 & \\
\hline
\end{tabular}

The thought of sex with a partner makes our participants feel OK in $69 \%$ of cases. Only $7.8 \%$ feel anxious while $23.2 \%$ feel themselves excited. When asked whether they openly discuss with their partner the emotions they have, $61.8 \%$ stated yes, they speak openly and $30 \%$ do not speak at all with their partner. They talk about sex only when really need to in $49.8 \%$ of cases. Never talk about sex frequently found at $10.4 \%$. Sex with partner found to be very satisfied or satisfied in a majority of cases because only $4.4 \%$ declared it as a not satisfying. Being naked in front of their partner is not a big problem because $69.4 \%$ feels themselves very comfortable and $25.8 \%$ felt only a little uncomfortable.

The foreplay is an important part of intimacy that is almost determinant of the course of sexual activity and the intensity of pleasure. In the questionnaire was the question about the application of the foreplay from which we received these answers: very often found to be $60.2 \%$, sometimes $27.8 \%$ and never in $12 \%$ of all cases. Talking about sex make our participants happy and relaxed in a majority of cases while embarrassed and ashamed used to be $4.4 \%$. When it comes to how a partner feels about their sex life $60.4 \%$ think that know they are satisfied, while $34.4 \%$ hope they are satisfied. Very good and good filings during sex were used to be in a majority of participants, because only $6 \%$ were anxious and uncomfortable. Talking about sex with parents in our region is still a taboo. It was proven in this study when the $81 \%$ of them have never spoken with their parents. There are many benefits when parents do address the topic of sex with their children. Parents can gauge their child's physical, 
emotional and psychological development and can tailor conversations to their needs and developmental level. Conversations about sex can build on information over time and at a pace that works for the child. And when parents express clear values about sex, children are more likely to adhere to those values.

Partners sometime argue inside the relationship. Our subjects declared to resolve it pretty easily by $28.8 \%$, while $65.4 \%$ of them can resolve their problems depends on the disagreement. Only $5.8 \%$ cannot resolve their fights. Trying something new sexually used to be taken into consideration at $67 \%$ while $7.4 \%$ feel immediately anxious. Feeling dissatisfied about something in sexual life will initiate talks with partner among $65.2 \%$ while $18.8 \%$ hope the problem fixes itself. When having sex $83.4 \%$ feels to be emotionally close to the partner. Imagining sex with people outside relationship were frequently at $13.2 \%$, sometimes $30.7 \%$ while never at $56.1 \%$ of our participants (Table 3).

Table 3

Participants expressions, emotions and feelings

\begin{tabular}{lccc}
\hline Questions 1 -15 & A & B & C \\
\hline $\begin{array}{l}\text { The thought of sex } \\
\text { with }\end{array}$ & Exited & OK & Anxious \\
$\begin{array}{l}\text { my partner makes me } \\
\text { feel }\end{array}$ & $23.20 \%$ & $69 \%$ & $7.80 \%$ \\
\hline $\begin{array}{l}\text { Discussing emotions } \\
\text { my partner and I ... }\end{array}$ & $\begin{array}{c}\text { Are very open } \\
61.80 \%\end{array}$ & $\begin{array}{c}\text { If there's a fight } \\
8.20 \%\end{array}$ & $\begin{array}{c}\text { Don't talk } \\
30 \%\end{array}$ \\
\hline & & When we really & \\
We talk about sex & Fairly regularly & need & Never \\
& $39.80 \%$ & $49.80 \%$ & $10.40 \%$ \\
\hline $\begin{array}{l}\text { I find sex with my } \\
\text { partner }\end{array}$ & Very satisfying & Pretty satisfying & Not satisfying \\
& $63.40 \%$ & $32.20 \%$ & $4.40 \%$ \\
\hline $\begin{array}{l}\text { Being naked with } \\
\text { my } \\
\text { partner makes me }\end{array}$ & $\begin{array}{c}\text { Total } \\
\text { feel ... }\end{array}$ & A little & Very \\
\hline $\begin{array}{l}\text { We touch, kiss, } \\
\text { hug and } \\
\text { express physical } \\
\text { affection }\end{array}$ & $69.40 \%$ & uncomfortable & uncomfortable \\
\hline
\end{tabular}




\begin{tabular}{|c|c|c|c|}
\hline $\begin{array}{l}\text { Talking about sex } \\
\text { makes me fel... }\end{array}$ & $\begin{array}{l}\text { Happy and } \\
\text { relaxed } \\
75.40 \%\end{array}$ & $\begin{array}{c}\text { A little awkward } \\
20.20 \%\end{array}$ & $\begin{array}{c}\text { Ashamed } \\
4.40 \%\end{array}$ \\
\hline $\begin{array}{l}\text { How my partner } \\
\text { feels about our sex } \\
\text { life }\end{array}$ & $\begin{array}{l}\text { They're } \\
\text { satisfied } \\
60.40 \%\end{array}$ & $\begin{array}{c}\text { Mostly satisfied } \\
34.40 \%\end{array}$ & $\begin{array}{l}\text { Aren't satisfied } \\
5.20 \%\end{array}$ \\
\hline During sex I feel ... & $\begin{array}{c}\text { Great } \\
46.20 \%\end{array}$ & $\begin{array}{c}\text { Good, usually } \\
47.80 \%\end{array}$ & $\begin{array}{c}\text { Anxious } \\
6 \%\end{array}$ \\
\hline $\begin{array}{l}\text { Growing up, my } \\
\text { parents } \\
\text { and I talked about } \\
\text { sex ... }\end{array}$ & $\begin{array}{l}\text { Openly, } \\
\text { regularly } \\
3 \%\end{array}$ & $\begin{array}{c}\text { Occassionally } \\
15.20 \%\end{array}$ & $\begin{array}{c}\text { Never. No way! } \\
81.80 \%\end{array}$ \\
\hline $\begin{array}{l}\text { Argues with my } \\
\text { partner } \\
\text { we can resolve ... }\end{array}$ & $\begin{array}{c}\text { Pretty easily } \\
28.80 \%\end{array}$ & $\begin{array}{c}\text { Depends disagre } \\
65.40 \%\end{array}$ & $\begin{array}{c}\text { We don't resolve } \\
5.80 \%\end{array}$ \\
\hline $\begin{array}{l}\text { If my partner want to } \\
\text { try } \\
\text { something new } \\
\text { sexually, I }\end{array}$ & $\begin{array}{l}\text { I talk it over } \\
67 \%\end{array}$ & $\begin{array}{c}\text { A little awkward } \\
25.60 \%\end{array}$ & $\begin{array}{c}\text { Immediately } \\
\text { anxious } \\
7.40 \%\end{array}$ \\
\hline $\begin{array}{l}\text { If feel dissatisfied } \\
\text { about } \\
\text { something in sex life } \\
\text { I... }\end{array}$ & $\begin{array}{l}\text { Talk with } \\
\text { partner } \\
65.20 \%\end{array}$ & $\begin{array}{l}\text { Put up for later } \\
16 \%\end{array}$ & $\begin{array}{c}\text { Hope fixes itself } \\
18.80 \%\end{array}$ \\
\hline $\begin{array}{l}\text { I feel emotionally } \\
\text { close } \\
\text { when I'm having sex } \\
\ldots\end{array}$ & $\begin{array}{c}\text { Yes } \\
83.40 \% \\
\end{array}$ & $\begin{array}{c}\text { I'm not sure } \\
12.80 \% \\
\end{array}$ & $\begin{array}{c}\text { Not satysfying } \\
3.80 \% \\
\end{array}$ \\
\hline $\begin{array}{l}\text { I imagine sex outside } \\
\text { of my relationship ... }\end{array}$ & $\begin{array}{l}\text { Rarely } \\
56.10 \%\end{array}$ & $\begin{array}{l}\text { Sometimes } \\
30.70 \% \\
\end{array}$ & $\begin{array}{c}\text { A lot } \\
13.20 \%\end{array}$ \\
\hline
\end{tabular}

Generally, we have found that our participants feel great or usually good during sex with the partners. But there was a difference between age groups. The youngest population (up to 20 year) feel great by $84.6 \%$ of subjects. On the age group between $21-50$ the majority $(52.1 \%)$ was found to feel great while participants over 50 years by $17.5 \%$ only, feel great whereas 75.3\% usually feel good. Third age group has a highest number of participants who feel anxious and uncomfortable, (table 4). This can be explained due to the correlation between age and sexual dysfunctions which can lead to the painful sexual activities and fear from new experimenting. 
Table 4

Description of fillings when having sex between age-groups

During sex I feel ....

\begin{tabular}{ccccc}
\hline \multirow{2}{*}{ Age (year) } & Great & Good, usually & Anxious and & uncomfortable \\
& 11 & 1 & 1 & Total \\
$0-20$ & $84.6 \%$ & $7.7 \%$ & $7.7 \%$ & 13 \\
& 203 & 165 & 22 & $390.0 \%$ \\
$21-50$ & $52.1 \%$ & $42.3 \%$ & $5.6 \%$ & $100.0 \%$ \\
& 17 & 73 & 7 & 97 \\
$50+$ & $17.5 \%$ & $75.3 \%$ & $7.2 \%$ & $100.0 \%$ \\
& 231 & 239 & 30 & 500 \\
Total & $46.2 \%$ & $47.8 \%$ & $6.0 \%$ & $100.0 \%$ \\
\hline & & $\mathrm{p}<0.005$ & &
\end{tabular}

Imagining sex with others is quite often occurrence especially between partners when one of them has a problem to concentrate into the present partner body in order to have more satisfaction. In our study male participants imagine an outside partner at $18.5 \%$ whereas this alternative among female sex was only $8.8 \%$. Female participants, $75.1 \%$ declared that never imagine sex with other partner compare to males where this percentage is only $33.5 \%$, (table 5). This could be explained by cultural, social and religious impact in overall population sexuality thoughts and beliefs.

Table 5

I imagine sex with people outside of my relationship

\begin{tabular}{ccccc}
\hline Sex & Never & Sometimes & A lot & Total \\
& 205 & 44 & 24 & 273 \\
Female & $75.1 \%$ & $16.1 \%$ & $8.8 \%$ & $100.0 \%$ \\
& 76 & 109 & 42 & 227 \\
\multirow{2}{*}{ Male } & $33.5 \%$ & $48.0 \%$ & $18.5 \%$ & $100.0 \%$ \\
& 281 & 153 & 66 & 500 \\
\cline { 2 - 5 } Total & $56.2 \%$ & $30.6 \%$ & $13.2 \%$ & $100.0 \%$ \\
\hline & & $\mathrm{p}<0.005$ & &
\end{tabular}




\section{Discussion}

To our knowledge, this is the first study in our Region ammong the few studies in the literature to evaluate sexual and intimacy sexual life using specific instrument for sexual life audit in various age group of population and through this results to determine approximately the personality characteristics. Our study shows that through sexual life audit we can hypothesize in which of Big Five factor our subjects belong. Analyzing the previous studies, which included data from more than 400,000 participants, the researchers came to the conclusion that personality influences sexuality in several different ways. (Ott-Holland, 2013).

Though the World Health Organization's definition of sexual health as a state of well-being, public health research yet has not examined sexual wellbeing outcomes, including sexual satisfaction. Sexual issues are among the most important issues in martial life, and adaptation in sexual relationship is counted as the element that influences happiness. One of the current issues in the domain of sexual relationship is sexual satisfaction which is among the dimensions of general quality of life. Various factors influence individuals' sexual function and the improvement of its quality.

As it was shown in our study the majority of answers are at Mostly $A$ section. It means that participants and their partners have a really healthy and positive sex life. They are intimate with each other and open with their emotions, comfortable in each other's company and in expressing affection. They are ready to talk openly about any areas and able to negotiate around the differences. This help them to feel close and intimate which contribute to strong personality. The good personality helps them to maintain what they have and regular date nights can keep the relationship feeling special. They are ready to explore new things together.

If we have a look into the conscientious people, they are more sexually satisfied and are less likely to develop sexual problems, perhaps because their attention to detail carries over into the bedroom in ways that enhance sex. As they tend to be conformists, it makes sense that they 
tend to report more conservative sexual attitudes. People who are more extraverted tend to be more sexually active. They not only report more desire for sex (and more frequent sexual fantasies), but they are doing it more often, too, which includes having more casual sex. So, our subjects with mostly A response should be spread within those two categories of personality. The results in the study conducted by Firoozi (2016) about the relationship between personality traits and sexual self-esteem showed an association between most of the personality traits and sexual self-esteem as well as the capability of these dimensions in prediction of women's sexual self-esteem. As sexual self-esteem is one of the most important factors in couples' sexual relationship and martial life satisfaction, adaptation of NEO personality before marriage counseling for those who have no previous sexual problems can help the counselors to detect high-risk women or those with low sexual self-esteem and suggest them appropriate strategies

According to Llaneza (2011) female sexuality is modulated by life events, reproduction, health, relationships and cultural factors. One-third of women in the Western world display some degree of sexual disorders. We are sure that this could be due to not satisfied sexual life and enough intimacy. The human's sexual desires is too merged with their total personality, so talking the sexual desire as an independent phenomenon is in fact impossible. The sexual identity, sexual bias and sexual behavior effect on evolution of one's personality and performance. Thus, the expression "psychosexual" in psychiatry is applied to describe the growth, personality function and effect of sexual desires on the same (Nasrollahi, 2011).

On a survey with 2168 university students in the United States, Higgins asked to rate their physiological and psychological satisfaction with their current sexual lives. Many respondents reported that they were either satisfied (approximately half) or very satisfied (approximately one third).She also mentioned that factors consistently associated with satisfaction in adults 
may not influence sexual satisfaction in the same way for young people just beginning their sexual lives, (Jenny A.Higgins, 2011).

Wallace (2008) concluded that sexuality (the physical and emotional responsiveness to sexual stimuli) goes beyond the sexual urge and sex act. For many older people it offers the opportunity to express not only passion but affection, esteem, and loyalty. It provides affirmative evidence that one can count on one's body and its functioning. It allows people to assert themselves positively. It carries with it the possibility of excitement and romance; it expresses delight in being alive.

The one third of particpants are Mostly B satisfied which menas that while they are mostly satisfied with sex life, it sounds like sometimes they can feel a little disconnected. Maybe there are things that they would like to change, but they are not sure how to start the conversation. Perhaps they feel awkward about it or are worried about hurting the partner's feelings. Likewise, it sounds like there is a bit of an emotional gap between partners. Maybe they are open with emotions in the whole, but perhaps they avoid certain topics, such as satisfaction due to different circumstances or health conditions. Sometimes only the focus on the emotions, by an impolite request is less likely to make partner feel defensive. Sending to the partner a message with lovely contents will help boost them to relax, imagine and increase sexual desire. Where there is a specific sexual problem, a small misunderstanding or things get wrong after different conflicts, there could be a benefit from sex therapy like mindfulness or couple therapy. Those specifics of the mostly B answers group are more or less the same as the agreeable people who seem less interested in sex and less desire, less frequent sex, and less casual sex. The fact that they are not as sexually active probably explains, in part, why agreeable people have fewer Sexualy Transmited Infections (although this may also be because agreeable people just take more steps to protect themselves and their partners due to their caring nature). Schaffhuser (2014) in his longitudinal study conducted in Switzerland, satisfaction 
in intimate couples was positively correlated with conscientiousness. Sayehmiri (2020) about this personality trait found that people high in agreeableness and conscientiousness refrain from showing aggression and are capable of controlling their impulses in marital relationship. McCllealand (2010), conducted a study about sexual life and come to the conclusion that over the past 20 years, sexual quality of life has become of increasing interest to psychologists studying quality of life with ill and/or aging populations. As people are living longer with chronic illnesses, the maintenance of sexual health has become a topic of concern and an essential domain of overall quality of life. Sexual interest and activity remain throughout older adulthood as established by studies done by Masters and Johnson (1986) and Lindau and colleagues (2007). An older adult's expression of sexuality may be restrained by functional limitations, normal aging changes, chronic health conditions such as cardiac disease, arthritis, diabetes, depression, incontinence, as well as environmental issues that exist in institutional living or limit contact with others ( Smyth, 2018). Sexuality assessment and considerations in older adults is sorely lacking in medical care and rehabilitation, let alone in older adults who reside in long term care facilities (Lichtenberg, 2014). Specifically, all health care team members, including occupational therapists, need to be more sensitive to the sexual desires and needs of older adults. Among middle-aged Chinese women, sexual desire is lower in 56 to 60year-old women, compared with those aged 45 to 55 years, whereas vaginal dryness and dyspareunia become more prevalent with age. Importantly, sexual function is associated with vaginal maturation status in women at midlife (Zhang, 2007)

Our participants at the age above 50 years declared their sexual life and intimacy mainly as good usally, which is really good if we have in consideration those conclusions. Here is a place to consider this population in our study belong to Conscientious people who tend to be very self-disciplined and detail-oriented. They prefer for things to be scheduled rather than spontaneous, and they tend to hold more conventional and traditional attitudes across the board. 
Mostly $C$ anserw is found to be among $14.4 \%$ of particpants. It seems like there is a real distance between the partners, both sexually and emotionally. Maybe they feel unable to talk about sex openly. Perhaps trying makes them feel extremely awkward, or they worry they are going to feel rejected if their partner says they are not satisfied. Perhaps even the thought of sex makes them anxious. Perhaps things have got to the point where they feel generally uncomfortable around each other where day-to-day tensions make life difficult and stressful. People high on the personality trait of neuroticism had more symptoms of sexual dysfunction, as well more negative emotions surrounding sex and more sexual dissatisfaction. This makes sense given that neuroticism is essentially a measure of people's tendency to experience negative emotions like worry, sadness and anger. Neurotic individuals tend to be on the emotionally unstable side. They do not handle stressful situations well and even very minor annoyances can put them in a bad mood. This could be a place for our subjects with mostly $\mathrm{C}$ answers because their left things to go to the point where they feel generally uncomfortable around each other where day-to-day tensions make life difficult and stressful. The data to support this findings are presented by Firoozi (2016) who mentioned that neuroticism as a personality trait includes sensitivity to having unreal beliefs, poor control of desires, and the tendency to experience psychological disorder in the form of anxiety, anger, depression, shyness, hatred, and a range of negative emotions. Higher scores in neuroticism are accompanied by lack of emotional stability and negative emotions such as fear, sorrow, being at a loss, anger, feeling guilty, and hatred. The findings by Sayehmiri (2020) indicated that the highest correlation was between marital satisfaction and conscientiousness, and the lowest correlation was between marital satisfaction and neuroticism. He also mentioned that neuroticism reduced marital satisfaction and people high in neuroticism tend to display negative behavior towards their partners that in turn reduces marital satisfaction in both partners. 
Realtionship and emotions related with age as it was shown that older subjects had lees great feelings. This is found also in the study conducted by Kinsberg (2000), where is stated that aging has a powerful impact on the quality of relationships and sexual functioning. The psychological impact of aging after midlife is a particularly timely topic given improved medical and psychological understanding of sexuality in both women and men, as well as more effective treatment for age-related sexual dysfunctions.

Researchers have examined the role of trait mindfulness and feelings in enhancing healthy sexual relationships through greater intimacy and diminished cognitive distraction which may contribute to healthy relationships and wellbeing. Maintaining satisfying romantic relationship and sex life contributes to physical and mental wellbeing (Lucas, 2012).

Prejudice was related with lack of communication between parents and children. Observed results supported our hypothesis that participants who reported open communication styles with parents demonstrated higher levels of knowledge and comfort about sexual topics than participants who reported avoidant communication styles. Practitioners can utilize this information by educating and encouraging the use of open communication by parents (Fitzharris, 2004). There are still barriers in terms of parent-adolescent engagement on issues related to risks associated with sexual behaviors and erroneous reproductive health choices among adolescents. Therefore, there is a need to encourage engagement by creating neutral platforms facilitated by community healthcare providers and/ or social workers, (Motsomi, 2016).

Vommas (2012) results in a Greek population study indicate that age plays an important role in sexual function for both sexes. Higher incidence of sexual dysfunction was observed in patients more than 65 years old compared to their younger counterparts. This corresponds well with the literature mentioned by Wommas (2012), which documents that in the general 
population, aging has a negative effect on sexual function. Nevertheless, older adults consider sexual function an important element of their Quality of Live.

Lutkievicz (2013) conducted a study which indicates that the subjective assessment of sexual life is related to the assessment of marital relation on the scale of emotional expression and relation coherence. No relation of sexual activity and sexual life with the assessment of the quality of marital relation was proved. However, the assessment of sexual life is related significantly to the assessment of the quality of marital relation. (Allen, 2018) conducted a meta-analytic review which addresses whether the major dimensions of trait personality relate to components of human sexuality. Mean effect sizes from 100 separate meta-analyses provided evidence that personality relates to theoretically predicted components of sexuality and sexual health.

In our study we did not ask for sexual orientation among participants so we couldn't know if there are diferences between them. The reason for unaddressing the sexual orientation was the lack of this issue on the used questionaire. Kwiatkowski (2015) concluded that Sexual orientation is responsible for differences in personality traits of the studied group to a greater extent than their biological sex.

\section{Conclusions}

Satisfaction with sexual life and intimacy, as a critical element of sexual health and as a potential correlate of several other health indicators, deserves more attention in scientific research. We have found that several factors (such as relationship, emotions, feelings, prejudice and sexual guilt) are related with sexual satisfaction in our sample of respodents. Relationship and emotions in relation with age as it was shown that older subjects had lees great feelings. Feelings could be related with subjects with answer mostly A because of great satisfaction with sexual life. Prejudice was related with lack of communication between parents and children. 
However, we can conclude that more than half of respodents are satisfied with their sexual life and intimacy. Finally, this descriptive study contributes to further empirical evidence debunking popular myths about gender, sexual satisfaction, and sexual health due to the atempt of putting them inside to the specific personality characteristics and, wath is more relevant for this area, breaking the taboo for speaking about sexual life satisfaction .

Talking about sex with parents is still minimized or taboo issue which can led to different bad habits and difficulties in the adolescence. This happens because the role of social, cultural and religious factors into families is very huge and due to lack of sexuality education in school and family. Psychologist may play a crucial role educating parents and children giving them advices and skills how to communicate about sexuality.

As in other studies in psychology, ours also tell us something about what shapes people's sense of sexuality, but this is not the whole story. Further prospective studies with both qualitative and quantitative method of data collection is recommended.

\section{Limitation of the study}

First, the study sample is homogeneous and relatively too small to draw any definite conclusions. In our sample, we did not report a normal characteristics of the Big Five traits but tried to put our subjects in some of those characteristics, what was not so easy. The sexual orientation was not included in the study because it was not included in a standard used questionaire otherwvise it will be with interest to see the possible correlation with the oppennes chacteristics of personality. Also some other labels were not used in the study to assess sexual behaviours as it is anal sex or masturbation which could cover a wide range of different behaviours.

Authors declare no conflict of interest! 


\section{References}

Wallace, M. How to Try This: Assessment of Sexual Health in Older Adults. The American Journal of Nursing, 108(7), 52-61; 2008.

Aaron M. Why Personality Holds the Key to Understanding Sexuality. Psychology today. 2017.

McClelland S. Social and Personality Psychology Compass. Blackwell Publishing Ltd. 2010 Nomejko Agnieszka, Grażyna Dolińska-Zygmunt. The Sexual Satisfaction Questionnaire psychometric properties. Polish Journal of Applied Psychology, vol. 12 (3), 105$112 ; 2014$

The Guardian. Are you happy in the bed. Take the sex test. UK. https://www.theguardian.com/lifeandstyle/2019/may/18/are-you-happy-in-bed-takesex-test; 2019.

Lichtenberg P. A. Sexuality and physical intimacy in long-term care. Occupational therapy in health care, 28(1), 42-50; 2014.

A.Baum, T.A. Revenson, \& J. Singer. Handbook of Health Psychology. Pp. 245-267). New York: Taylor \& Francis. Forthcoming. 2012

Higgins, J. A., Mullinax, M., Trussell, J., Davidson, J. K., Sr, \& Moore, N. B. Sexual satisfaction and sexual health among university students in the United States. American journal of public health, 101(9), 1643-1654; 2011.

Fanta, T., Haile, K., Abebaw, D., Assefa, D., \& Hibdye, G. Assessment of sexual dysfunction and associated factors among patients with schizophrenia in Ethiopia, BMC psychiatry, 18(1), 158;2018

Lutkiewicz, K. \& Bidzan, M. Sexual activity of pregnant Polish women and the assessment of the marital relation quality. Health Psychology Report, 1, 9-17; 2013.

Farideh Mogharab et al.Assessment of Self-report on sexual life of married reproductive-age women in Iran. Ambient Science: Vol. 06h (1); 16-20. 2019.

So, H. W. \& Cheung, F. M. Applicability of sex therapy for Chinese couples with sexual dysfunction. Journal of Sex Research, 42 (2), 93-101.) 2005.

Zhang C, Cui L, Zhang L, Shi C, Zang H.Sexual activity and function assessment in middleaged Chinese women using the female sexual function index. Menopause. 2017 Jun; 24(6):669-676; 2017.

Marcin Kwiatkowski, Iwona Lidia Janicka. Personality of Polish gay men and women. current issues in personality psychology. Volume 3(4), 2015. 
Bita Nasrollahi, Keyvan Darandeganb, Azar Rafatmah. (2011). The relationship between personality traits and sexual variety seeking. Procedia - Social and Behavioral Sciences 30 - 1399 - 140.; 2011.

Allen, M. S., \& Walter, E. E. Linking big five personality traits to sexuality and sexual health: A meta-analytic review. Psychological Bulletin, 144(10), 1081-1110; 2018.

Bouchard, K.N., Stewart, J.G., Boyer, S.C., Holden, R.R., \& Pukall, C.F. Sexuality and personality correlates of willingness to participate in sex research. The Canadian Journal of Human Sexuality 28(1), 26-37. 2019.

Llaneza, Placido et al. Sexual Function Assessment in Postmenopausal Women with the 14Item Changes in Sexual Functioning Questionnaire. The Journal of Sexual Medicine, Volume 8, Issue 8, 2144 - 2151, 2011.

Ott-Holland, C. J., Huang, J. L., Ryan, A. M., Elizondo, F., \& Wadlington, P. L.Culture and Vocational Interests: The Moderating Role of Collectivism and Gender Egalitarianism. Journal of Counseling Psychology. 2013.

Firoozi, Mahbobe et al. "The relationship between personality traits and sexual self-esteem and its components." Iranian journal of nursing and midwifery research vol. 21,3 2016.

Schaffhausen K, Allemand M, Martin M. Personality traits and relationship satisfaction in intimate couples: three perspectives on personality. Eur J Personal. 28(2):120 -33; 2014.

Sayehmiri, K., Kareem, K.I., Abdi, K. et al. The relationship between personality traits and marital satisfaction: a systematic review and meta-analysis. BMC Psychol 8, 15. 2020.

Kingsberg SA. he psychological impact of aging on sexuality and relationships. J Womens Health Gend Based Med.Vol;9 Suppl 1:S33-8. 2000.

Fitzharris, J. L., \& WernerWilson, R. J. Multiple perspectives of parent adolescent sexual communication: Phenomenological description of a Rashoman effect. American Journal of Family Therapy, 34(4); 2004.

Motsomi, Kegaugetswe et al. "Factors affecting effective communication about sexual and reproductive health issues between parents and adolescents in zandspruit informal settlement, Johannesburg, South Africa.” The Pan African Medical Journal vol. 25 120. 2016. 
Oेмив LU Wimblu, Rev. Estud. de Psicología UCR, 15(1) 2020 (Enero-Junio): 49-71 /ISSN: 1659-2107

Lucas M . Rewire your brain for love: Creating vibrant relationships using the science of mindfulness. New York, NY: Hay House. 2012.

Ahadi B. Relationship between personality and marital satisfaction. Contemporary Psychology. 2:32-6; 2008. 